\title{
Surgical management of acquired tracheo/bronchoesophageal fistula associated with esophageal diverticulum
}

\author{
Yifeng Sun ${ }^{1 *}$, Shuguang Hao ${ }^{2 *}$, Yu Yang ${ }^{1}$, Xufeng Guo ${ }^{1}$, Bo Ye ${ }^{1}$, Xiaobin Zhang ${ }^{1}$, Zhigang Li $^{1}$ \\ ${ }^{1}$ Department of Thoracic Surgery, Shanghai Chest Hospital, Shanghai Jiaotong University, Shanghai 200030, China; ${ }^{2}$ Department of Thoracic \\ Surgery, Xinxiang Center Hospital, Xinxiang 453000, China \\ Contributions: (I) Conception and design: Y Sun, Z Li; (II) Administrative support: Z Li; (III) Provision of study materials or patients: S Hao, Y Yang, \\ X Guo; (IV) Collection and assembly of data: X Zhang; (V) Data analysis and interpretation: B Ye; (VI) Manuscript writing: All authors; (VII) Final \\ approval of manuscript: All authors. \\ *These authors contributed equally to this work. \\ Correspondence to: Zhigang Li, PhD. Department of Thoracic Surgery, Shanghai Chest Hospital, Shanghai Jiaotong University, No. 241, Huaihaixi \\ Road, Shanghai 200030, China. Email: dr_lizhigang@163.com.
}

Background: The reports on acquired tracheoesophageal fistulas (TEFs) or bronchoesophageal fistulas (BEFs) associated with traction esophageal diverticula (TED) are rare. Here, we present our experience of six cases.

Methods: Between Jan. 2015 and Jun. 2016, 6 patients were admitted to our department for TEF/BEFs combined with esophageal diverticula. Clinical data of the 6 patients were retrospectively reviewed.

Results: All orifices of TEF/BEF in the esophagus side opened at the diverticula wall. The orifices in the airway side were 2 at the carina and 4 at the right intermediate bronchus. All six patients received the same intervention: a limited diverticulectomy with the fistula resection was done in the esophagus; separate layers of repair were performed for the defect in the esophagus; the muscle flap interposition was used in all six cases. All postoperative courses were uneventful. No recurrence fistula and symptomatic diverticula occurred. The airway and esophagus were patency during a median of 9-month follow-up.

Conclusions: Acquired TEF/BEFs caused by esophageal diverticula can be treated successfully by surgery. A limited diverticulectomy is sufficient to ensure enough esophagus remodeling.

Keywords: Tracheo/bronchoesophageal fistula (TEF/BEF); esophagus diverticulum; acquired

Submitted Dec 17, 2016. Accepted for publication May 14, 2017.

doi: $10.21037 /$ jtd.2017.09.81

View this article at: http://dx.doi.org/10.21037/jtd.2017.09.81

\section{Introduction}

Acquired tracheoesophageal or bronchoesophageal fistulas (TEFs or BEFs) is a rare disorder with a variety of conditions. The majority causes of acquired non-malignant TEFs or BEFs fistulas include postintubation injury, chronic infections (e.g., tuberculosis), radiation injury and postsurgical lesions $(1,2)$. Traction diverticulum results from external inflammatory reactions in neighboring mediastinal ganglia, the tissue adhesion to the esophagus that contracts and scars the wall of the esophagus to provoke the diverticulum. In rare cases, this causes inflammatory necrosis, and a fistula will appear between the diverticulum and the respiratory airways (3).

Surgical intervention for TEF/BEFs fistulas caused by diverticulum has been especially rare. From Jan 2015 to Jun 2016, six consecutive cases of acquired TEFs/BEFs through esophagus diverticulum were admitted to our institute and underwent operation. We review the presentation and management of six patients and include a literature review with a summary of surgical indications and operational techniques. 


\section{Methods}

Approval for the study was obtained from the Ethics Committee of Shanghai Chest Hospital [KS(Y) 1723]. Written informed consent was obtained from each patient or her legal representative.

\section{Case descriptions}

\section{Case 1}

The 67-year-old female patient developed a persisting cough while eating and signs of aspiration pneumonia for 6 months. The patient had a history of mid-esophageal diverticulum diagnosed for 30 years, with the symptom of regurgitation. An acquired TEF $0.5 \mathrm{~cm}$ proximal to the carina was detected on esophagoscopy and bronchoscopy. Upper GI series using gastrografin showed that the diverticula combined with a fistulous tract between the esophagus and the bronchial tree. A chest CT revealed pneumonia in the bilateral lung and bronchiectasis in the right low lobe. The patient received antibiotic treatment before operation.

\section{Case 2}

A 47-year-old female was admitted to our center with persistent cough of 2 years. Esophagoscopic evaluation demonstrated an orifice in the esophageal diverticulum, but bronchoscopy displayed normal. The esophagogram showed the leakage of gastrografin, and a chest CT scan revealed an image of contrast medium in the bronchus of the right low lobe right after esophagogram.

\section{Case 3}

A 78-year-old female patient was repeatedly hospitalized for persistent cough during the recurrent pulmonary infection over a period of 72 months. Esophagoscopy and bronchoscopy revealed a TEF $0.4 \mathrm{~cm}$ proximal to the carina. Esophagogram also showed the tract between the esophagus and airway conduit. CT scan showed severe bilateral pneumonia, and more serious in left inferior lobe. A nasogastric tube was inserted for nutrition intake and antibiotic treatment was managed on account of the pneumonia

\section{Case 4}

The 51-year-old female complained with cough after swallowing for 2 months. Esophagoscopy discovered a diverticulum $30 \mathrm{~cm}$ away from upper incisor in the anterior wall of esophagus, and an orifice in the top of diverticulum.
The esophagogram imaging exhibited contrast medium leakage to intermediate bronchus, and CT examination indicated bronchiectasis in inferior lobe of right lung.

\section{Case 5}

The patient is a 68 -year-old woman with diverticulum who complaint of a racking cough while eating and following chest tightness for 36 months. A fistula between esophagus and right intermediated bronchus was showed in upper GI series; esophagoscopy detected a diverticulum $25 \mathrm{~cm}$ away from upper incisor and an orifice in the top of diverticulum. Bronchoscopy evaluation showed obvious mucosa hypertrophy of intermediate bronchus and atelectasis of inferior and middle lobe of right lung was confirmed by chest CT scan.

\section{Case 6}

A 68-year-old female patient was confirmed BEF combined with diverticulum for 24 months and failed with two-times esophagus stent insertion and one time clip using. Nutrition intake was through a nasogastric tube for 12 months before admitting in our division. Orifice of fistula in diverticulum was $25 \mathrm{~cm}$ away from upper incisor through esophagoscopy evaluation. Esophagogram also showed the contrast medium tract, and CT scan showed pneumonia in inferior lobe of right lung.

Table 1 showed all patients' pre-operative demographics, and Figures 1-6 showed the esophagoscopy, bronchoscopy, pre- and post-esophagogram for patients 1-6.

\section{Surgical manipulations}

Dissection of the diverticulum and the fistulous tract was conducted through the right thoracotomy. Limited diverticulectomy and the adjacent inflammatory mass resection were performed. The fistulas were removed with suture closure of the tracheal/bronchus defects or lobectomy. Esophageal mucosa and muscle were separated and sutured for esophagomyotomy. Vascularized muscle flaps were interposed between the repaired esophageal and tracheal/bronchus defects.

\section{Postoperative complications and mortality}

Adverse events occurring in hospital within 30 days after surgery were defined as postoperative complications. Operative mortality was defined as death occurring within 30 days of the operation. 
Table 1 Patients' characteristics

\begin{tabular}{|c|c|c|c|c|c|c|}
\hline Characteristics & Case 1 & Case 2 & Case 3 & Case 4 & Case 5 & Case 6 \\
\hline Age & 65 & 46 & 78 & 51 & 68 & 54 \\
\hline Gender & Female & Female & Female & Female & Female & Female \\
\hline Symptom & Cough during eating & Persist coughing & $\begin{array}{l}\text { Coughing with } \\
\text { swallowing }\end{array}$ & $\begin{array}{l}\text { Cough during } \\
\text { eating }\end{array}$ & $\begin{array}{l}\text { Cough and oppression } \\
\text { in the chest }\end{array}$ & $\begin{array}{l}\text { Cough during } \\
\text { eating }\end{array}$ \\
\hline $\begin{array}{l}\text { Duration of symptom } \\
\text { (months) }\end{array}$ & 6 & 24 & 72 & 2 & 36 & 60 \\
\hline Physical examination & Bilateral pulmonary rale & Lung rale in RLL & $\begin{array}{l}\text { Bilateral } \\
\text { pulmonary rale }\end{array}$ & $\begin{array}{l}\text { Lung rale in } \\
\text { RLL }\end{array}$ & Lung rale in $R L L$ & Normal \\
\hline \multicolumn{7}{|l|}{ Esophagoscopy } \\
\hline $\begin{array}{l}\text { Location of } \\
\text { diverticulum (away } \\
\text { from upper incisor, } \\
\mathrm{cm} \text { ) }\end{array}$ & 26 & 30 & 28 & 30 & 25 & 23 \\
\hline $\begin{array}{l}\text { Orifice of fistula } \\
\text { (away from upper } \\
\text { incisor, } \mathrm{cm} \text { ) }\end{array}$ & 28 & 31 & 29 & 32 & 26 & 25 \\
\hline Bronchoscopy & $\begin{array}{l}\text { Orifice in trachea } 0.5 \mathrm{~cm} \\
\text { proximal to the carina }\end{array}$ & Normal & $\begin{array}{l}\text { Orifice in trachea } \\
0.4 \mathrm{~cm} \text { proximal to } \\
\text { the carina }\end{array}$ & Normal & $\begin{array}{l}\text { Mucosa hypertrophy of } \\
\text { intermediate bronchus }\end{array}$ & Normal \\
\hline $\begin{array}{l}\text { Upper Gl series by } \\
\text { using gastrografin }\end{array}$ & $\begin{array}{l}\text { Leakage to bilateral } \\
\text { pulmonary }\end{array}$ & Leakage & Leakage to RLL & Leakage & Leakage & Leakage \\
\hline Chest CT scan & Pneumonia & $\begin{array}{l}\text { Contrast medium in right } \\
\text { intermediate bronchus }\end{array}$ & Pneumonia & $\begin{array}{l}\text { Bronchiectasis } \\
\text { in RLL }\end{array}$ & Atelectasis in RIL + RML & $\begin{array}{l}\text { Pneumonia in } \\
\text { RIL }\end{array}$ \\
\hline FEV1 (L) & 1.86 & 2.11 & 1.78 & 1.83 & 1.29 & 2.17 \\
\hline FEV1/FVC & $89 \%$ & $96.3 \%$ & $91 \%$ & $75.2 \%$ & $59.9 \%$ & $92.9 \%$ \\
\hline DLCO-SB & $59.7 \%$ & $73.1 \%$ & $63.2 \%$ & $95.1 \%$ & $63.9 \%$ & $113.4 \%$ \\
\hline
\end{tabular}

RIL, right low lobe; RML, right middle lobe; FEV1, forced expiratory volume in one second; FVC, forced vital capacity; DLCO, carbon monoxide diffusing capacity.

\section{Results}

\section{Surgical procedure and postoperative outcomes}

Six patients received surgical therapy after improvements in nutritional status. During the operation, the surgeons found that the orifice airway conduit was located in the tracheal approach to the carina for two patients and in the intermediate bronchus for four patients. The orifice of the esophagus conduit was located in the diverticula for all patients. Limited diverticulectomy and the tracheal/ bronchus defects were repaired in five patients, and limited diverticulectomy with lobectomy of right lower lobe (RIL) + right middle lobe (RML) were performed in case 5, causing of the obvious mucosa hypertrophy of intermediate bronchus and completely atelectasis in RIL + RML. Intercostal muscles flap in two patients and serratus anterior muscular flaps in four patients were used to separate the esophagus and trachea/bronchus.

Operative bleeding ranged from 90 to $220 \mathrm{~mL}$, and operative time ranged from 95 to $210 \mathrm{~min}$. Pathologic examination of the resected specimen showed chronic inflammatory tissue surrounding the resected esophageal diverticulum and the adjacent bronchus. A nasogastric tube was placed at the duodenum for enteral nutrition. The esophagography was successfully performed on the $7^{\text {th }}$ postoperative day for all patients and no leakage from the esophagus was noted. Then, patients were encouraged to sip water and the oral intake were gradually increased until the patient could tolerate soft diet without parenteral nutrition. The length of hospital stay ranged from 8 to 20 days (post-operative information was showed in Table 2, No. (D) image of Figures 1-6 showed the post-operative esophagogram). No postoperative complication or mortality was observed. 


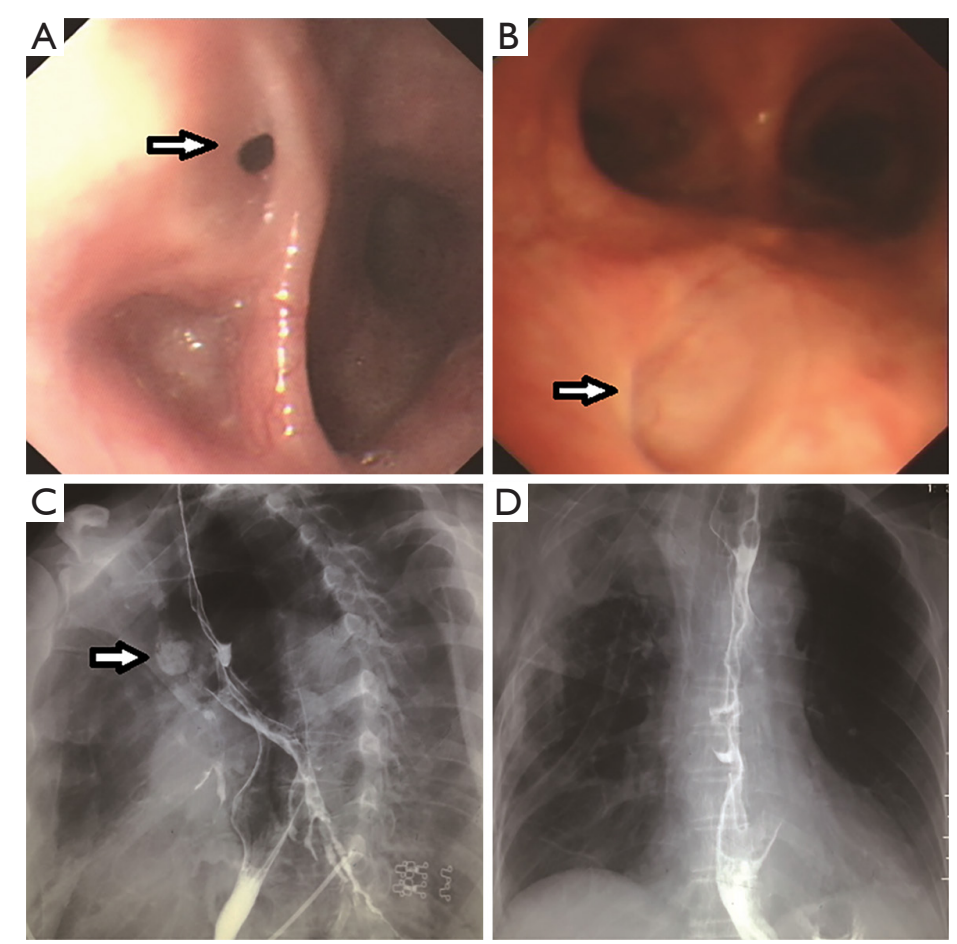

Figure 1 The images (A-D) showed the esophagoscopy, bronchoscopy, pre- and post-esophagogram of patient 1 . The arrows in the No. (A-C) images displayed the orifice in esophageal diverticulum under the esophagoscopic view, the orifice in airway lumen through bronchoscopic view and the leakage of contrast medium respectively.
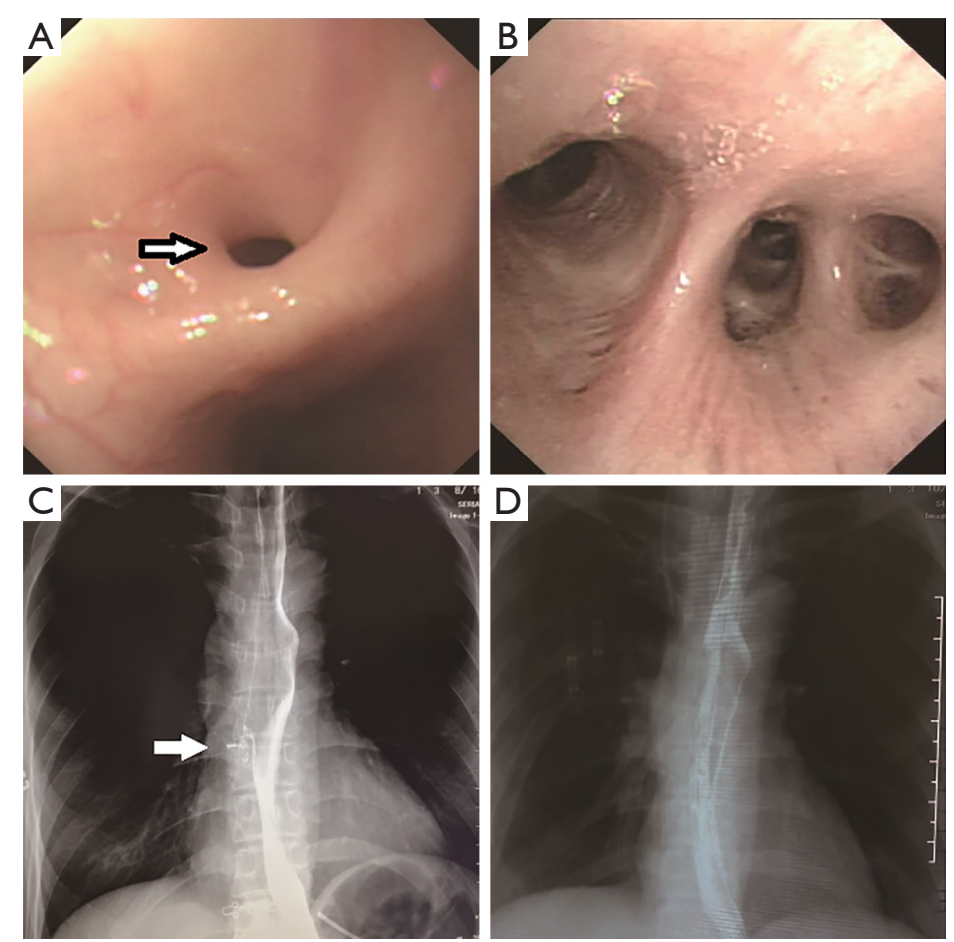

Figure 2 The images (A-D) showed the esophagoscopy, bronchoscopy, pre- and post-esophagogram of patient 2. The arrows in the No. (A,C) images displayed the orifice in esophageal diverticulum under the esophagoscopic view and the leakage of contrast medium respectively. No. (B) image showed normal bronchoscopy. 

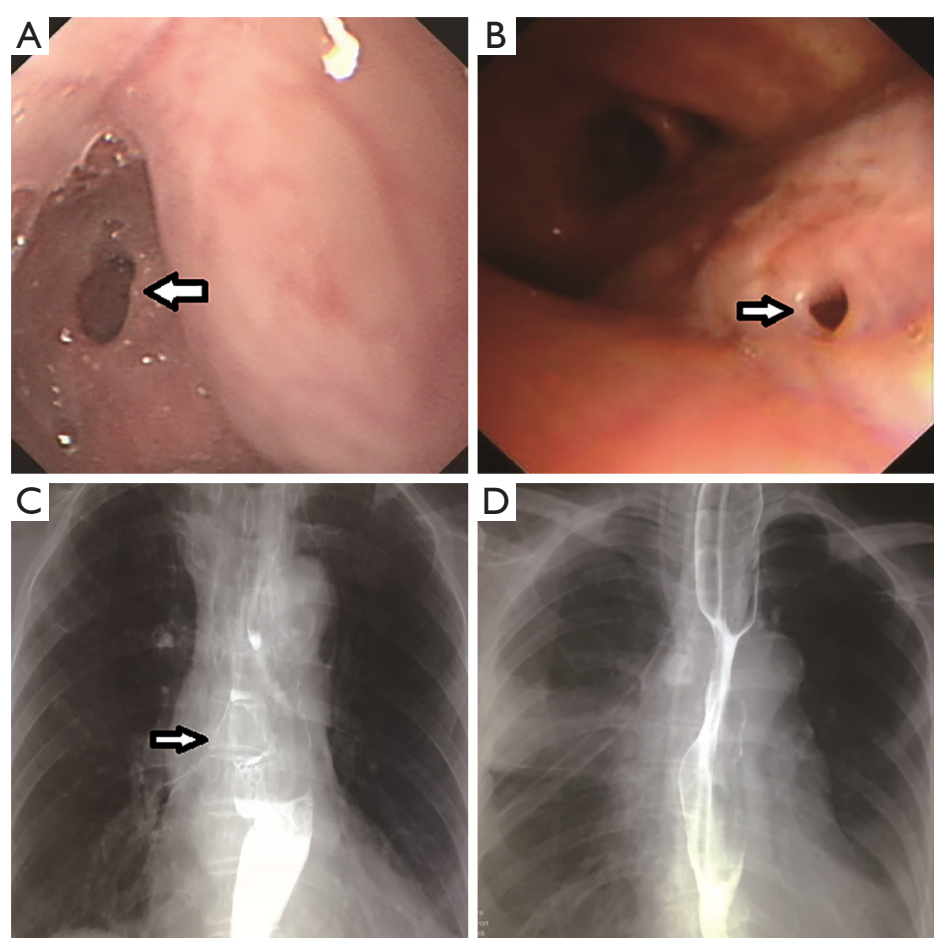

Figure 3 The images (A-D) showed the esophagoscopy, bronchoscopy, pre- and post-esophagogram of patient 3. The arrows in the No. (A-C) images displayed the orifice in esophageal diverticulum under the esophagoscopic view, the orifice in airway lumen through bronchoscopic view and the leakage of contrast medium respectively.
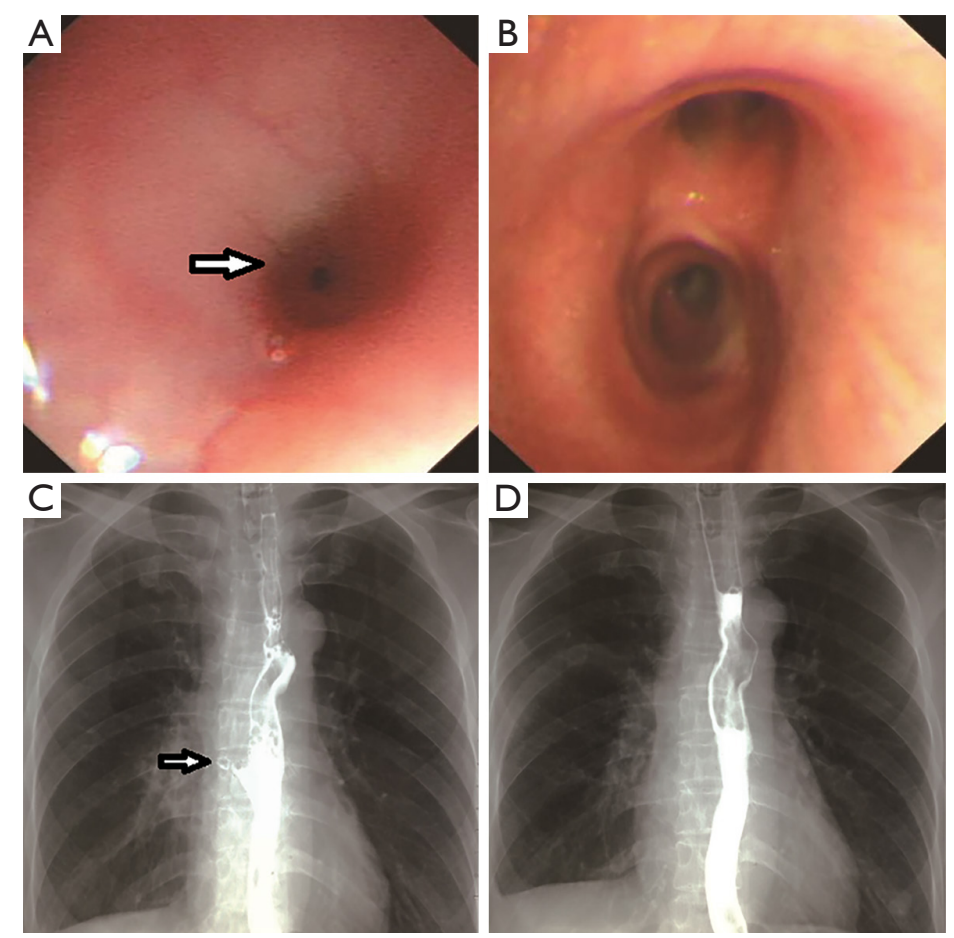

Figure 4 The images (A-D) showed the esophagoscopy, bronchoscopy, pre- and post-esophagogram of patient 4 . The arrows in the No. (A,C) images displayed the orifice in esophageal diverticulum under the esophagoscopic view and the leakage of contrast medium respectively. No. (B) image showed normal bronchoscopy. 


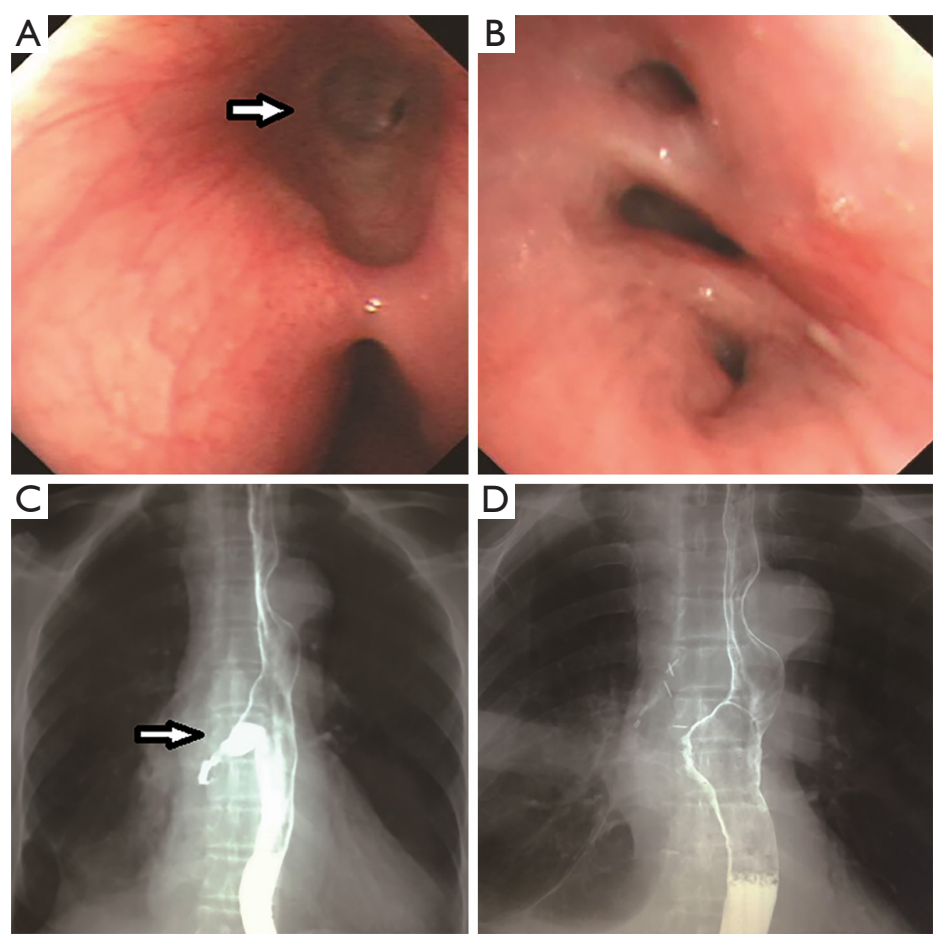

Figure 5 The images (A-D) showed the esophagoscopy, bronchoscopy, pre- and post-esophagogram of patient 5 . The arrows in the No. (A,C) images displayed the orifice in esophageal diverticulum under the esophagoscopic view and the leakage of contrast medium respectively. No. (B) image showed mucosa hypertrophy of intermediate bronchus.
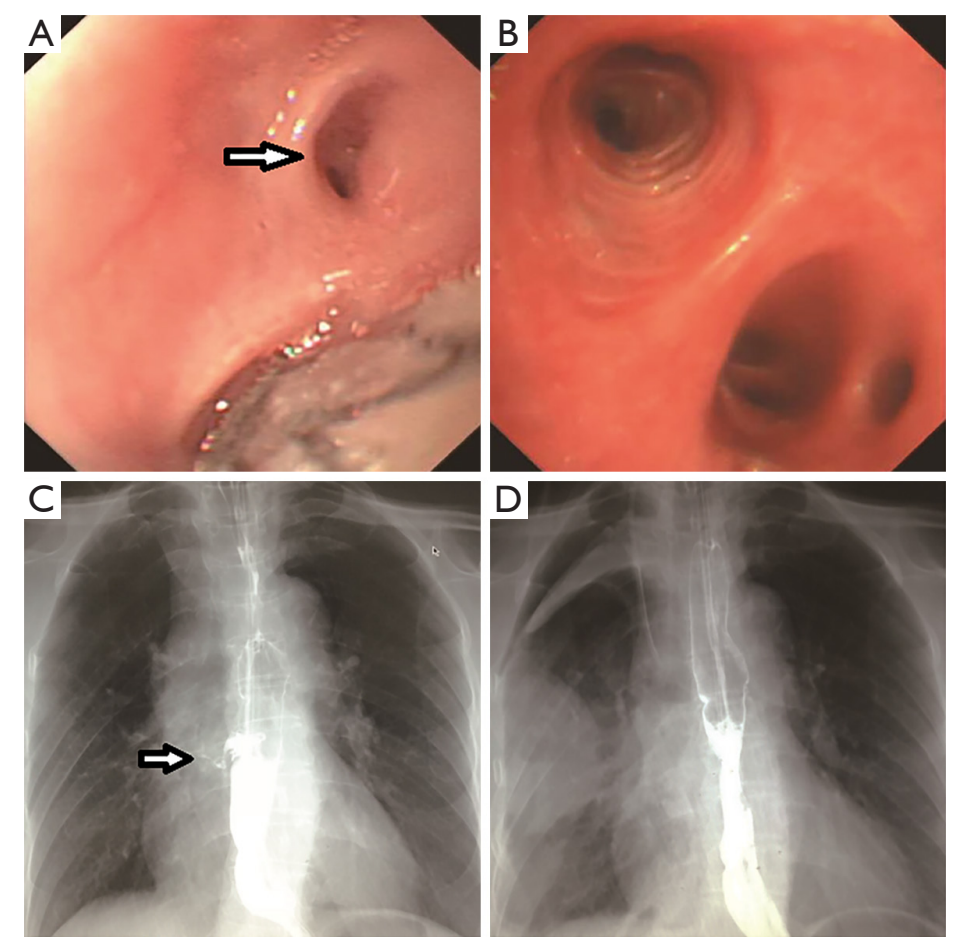

Figure 6 The images (A-D) showed the esophagoscopy, bronchoscopy, pre- and post-esophagogram of patient 6 . The arrows in the No. (A,C) images displayed the orifice in esophageal diverticulum under the esophagoscopic view and the leakage of contrast medium respectively. No. (B) image showed normal bronchoscopy. 


\begin{tabular}{|c|c|c|c|c|c|c|}
\hline Variables & Case 1 & Case 2 & Case 3 & Case 4 & Case 5 & Case 6 \\
\hline $\begin{array}{l}\text { Insider diameter of fistula } \\
(\mathrm{mm})\end{array}$ & 1.5 & 2 & 2 & 1.5 & 2 & 1.5 \\
\hline Length of fistula (mm) & 5 & 6 & 4 & 5 & 5 & 6 \\
\hline $\begin{array}{l}\text { Location of fistula in air } \\
\text { conduit }\end{array}$ & Trachea & $\begin{array}{l}\text { Intermediate } \\
\text { bronchus }\end{array}$ & Trachea & $\begin{array}{l}\text { Intermediate } \\
\text { bronchus }\end{array}$ & $\begin{array}{l}\text { Intermediate } \\
\text { bronchus }\end{array}$ & $\begin{array}{l}\text { Intermediate } \\
\text { bronchus }\end{array}$ \\
\hline $\begin{array}{l}\text { Surgical approach of } \\
\text { trachea/bronchus defective }\end{array}$ & $\begin{array}{l}\text { Limited } \\
\text { diverticulectomy } \\
\text { and closure } \\
\text { trachea defects }\end{array}$ & $\begin{array}{l}\text { Limited } \\
\text { diverticulectomy } \\
\text { and closure } \\
\text { bronchus defects }\end{array}$ & $\begin{array}{l}\text { Limited } \\
\text { diverticulectomy } \\
\text { and closure } \\
\text { trachea defects }\end{array}$ & $\begin{array}{l}\text { Limited } \\
\text { diverticulectomy } \\
\text { and closure } \\
\text { trachea defects }\end{array}$ & $\begin{array}{l}\text { Limited } \\
\text { diverticulectomy } \\
\text { and Lobectomy of } \\
\text { RML + RIL }\end{array}$ & $\begin{array}{l}\text { Limited } \\
\text { diverticulectomy } \\
\text { and closure } \\
\text { trachea defects }\end{array}$ \\
\hline $\begin{array}{l}\text { Surgical approach of } \\
\text { esophagus defective }\end{array}$ & 2-layer closure & 2-layer closure & 2-layer closure & 2-layer closure & 2-layer closure & 2-layer closure \\
\hline Muscle flap interposition & Serratus anterior & $\begin{array}{l}\text { Intercostal } \\
\text { muscles }\end{array}$ & Serratus anterior & $\begin{array}{l}\text { Intercostal } \\
\text { muscles }\end{array}$ & & Serratus anterior \\
\hline Operation time (min) & 180 & 210 & 155 & 150 & 160 & 95 \\
\hline Blood loss (mL) & 150 & 175 & 220 & 100 & 150 & 90 \\
\hline ICU stay (days) & 1 & 1 & 3 & 1 & 1 & 2 \\
\hline Chest tube duration (days) & 8 & 8 & 12 & 4 & 6 & 7 \\
\hline Transfusion (U) & 0 & 0 & 0 & 0 & 0 & 0 \\
\hline $\begin{array}{l}\text { Hospitalization (post- } \\
\text { operation) }\end{array}$ & 12 & 8 & 20 & 10 & 13 & 8 \\
\hline Complications & No & No & No & No & No & No \\
\hline Date of operation & Jan. 28, 2015 & Oct 16,2015 & $\operatorname{Jan} 1,2016$ & May 9, 2016 & May 20, 2016 & Jun 6, 2016 \\
\hline Follow-ups (months) & 21 & 12 & 9 & 5 & 5 & 4 \\
\hline
\end{tabular}

\section{Follow-up information}

Complete follow-up information was obtained for six cases. During a median follow up of 9 months, no patient experienced symptoms of fistula reoccurrence or esophageal stenosis.

\section{Discussion}

Benign BEFs in adults are uncommon; the most frequent etiologies for the fistulae are complications of postintubation injury and prior esophageal surgery. Traction esophageal diverticula (TED) is one kind of true diverticula that develops as the results of chronic inflammatory contracture from mediastinal structures outside the esophagus. Most TEDs occur in the upper middle of the thoracic esophagus in a peritracheal/bronchial location (4). Diverticula of the esophageal body comprise $10 \%$ to $15 \%$ of all esophageal diverticula. The natural history of midesophageal diverticula may lead to severe complications, such as erosions of the esophageal wall, and cause hemorrhage or perforation (5).
Surgical approach for acquired TEF/BEF caused by esophageal diverticulum was rarely reported in the literatures. There were five case reports by Braghetto et al. (6), Tomiyama et al. (7), López et al. (3), Akashi et al. (8), and Stewart et al. (9) in available literatures researching (Table 3).

Based on medical history, clinical manifestations, radiographic examination, esophagoscopy and bronchoscopy, the diagnosis of TEF/BEFs or esophageal diverticula is not difficult (10). Esophagogram with oral taking contrast medium is helpful role in the exact localization of the fistula track. As the main methods to diagnose TEF/BEF, esophagoscopy and bronchoscopy are able to identify the fistulas in most cases. However, recognition of the tracheal or bronchial orifice in some smaller fistulas could be challenging (11). In our study, there were three cases with normal-appearing and one case with mucosa hypertrophy in bronchoscopy examination despite of obvious symptom with cough during swallowing. Orally administered methylene blue before bronchoscopy or observation of bubbles leaked from the airway may be helpful to identify small fistulas (11). 
Table 3 Review of information on cases of esophagobronchial fistula due to esophageal diverticulum in the literatures

\begin{tabular}{|c|c|c|c|c|c|}
\hline Author & Year & Cases & Location of fistula & Surgical approach & Interposed muscle \\
\hline Tomiyama et al. (7) & 2003 & 1 & $\begin{array}{l}\text { Middle of the esophagus- } \\
\text { intermediate bronchus }\end{array}$ & $\begin{array}{l}\text { Tract excision and both ends of } \\
\text { fistula closed with ligation }\end{array}$ & $\mathrm{N} / \mathrm{A}$ \\
\hline Akashi et al. (8) & 1997 & 1 & $\begin{array}{l}\text { Middle of the esophagus-right } \\
\text { low lobe bronchus }\end{array}$ & $\begin{array}{l}\text { Both diverticulum and fistulous } \\
\text { closure to bronchus were divided } \\
\text { with endo-stapler }\end{array}$ & $\begin{array}{l}\text { Mediastinal pleural } \\
\text { patch }\end{array}$ \\
\hline Stewart et al. (9) & 1958 & 1 & $\begin{array}{l}\text { Middle of the esophagus- } \\
\text { superior segment of right } \\
\text { lower lobe }\end{array}$ & $\begin{array}{l}\text { Segment resection and diverticulum } \\
\text { excision }\end{array}$ & $\mathrm{N} / \mathrm{A}$ \\
\hline
\end{tabular}

The common symptoms of TEF/BEF include coughing while swallowing water (Ono's sign), fever, and/or weight loss. Continuous spillage of esophageal fluid into the tracheobronchial tree results in pneumonia, bronchial obstruction, atelectasis, and respiratory distress (12). Usually, repeated fever and poor food-in take lead to malnutrition of a patient. For patients with the Ono's sign associated pneumonia and infectious, the corrective procedure should be considered to close the fistulae with surgical management (13). However, for patients with small TEF/BEF that remain localized and symptomless, choosing active surgical intervention is still under debate. Devarbhavi et al. (14) documented that small TEF caused by esophageal tuberculosis can be treated safely with antituberculosis drugs alone.

Regarding surgical treatment for esophageal diverticula, the standard technique for TED is a long esophagomyotomy with diverticulectomy. For TED patients accompanied TEF/BEF, excision of the diverticulum and the fistulas with the adjacent inflammatory mass should be done. Employment of direct suture closure techniques of the tracheal/bronchus and esophageal defects with interposition of robust vascularized tissue is simple and sufficient (15). In our series, all patients fulfilled with limited diverticulectomy associated with tracheal/bronchus defects repair and the interposition of vascularized flaps, no recurrence fistula or symptomatic diverticula occurred during the follow-up period.

Isolated reports advocate initial management of nonmalignant TEF with endoscopic treatment, such as stent insertion or clip application. Jung et al. (16) described a successfully treatment of a quadriplegia patient with TEF through esophageal diverticulum by clipping under the esophagoduodenoscope on November 10, 2009. Schweigert et al. (17) also reported the recovery of three of four patients with benign gastro-tracheobronchial fistula treated by endoscopic stent insertion. Although endotherapy is a simple procedure for surgical application, controversy exists that endoscopic treatment could be definitively eliminated for acquired benign TEF. Buskens et al. (18) experienced failure in endoscopic treatment when attempting with a fibrin glue or hemostatic clips even in a patient with a long mediastinal fistula track. Muniappan et al. (2) advocated prompt surgical repair to control the fistula rather than depending on stents because stents may lead to significant granulation tissue and typically extend the airway injury. Bona et al. (19) recommended that endoscopic treatment should only be performed for patients with viable gastric tubes and no signs of mediastinitis or sepsis. To our best knowledge, we did not find similar literature on endoluminal stents in treating TEF through TED. The patients in our group were referred for surgical repair as a first choice after clear diagnosis. These nonsurgical invasive techniques may be of benefit for patients who decline or who are not candidates for surgery.

In summary, TEF/BEFs caused by traction diverticula is both rare and insidious. Early and definite surgical intervention is proposed once the diagnosis is confirmed. Single-stage limited diverticulectomy and direct suture repair of both the tracheal and esophageal defects with interposed muscle flaps can be performed successfully in TEF/BEFs patients caused by diverticulum. 


\section{Acknowledgements}

Funding: This study was granted by the Science and Technology Commission of Shanghai Municipality (No. 14411950800).

\section{Footnote}

Conflicts of Interest: The authors have no conflicts of interest to declare.

Ethical Statement: The study was approved by the Ethics Committee of Shanghai Chest Hospital [No. KS(Y) 1723] and written informed consent was obtained from all patients.

\section{References}

1. Altorjay A, Mucs M, Rüll M, et al. Recurrent, nonmalignant tracheoesophageal fistulas and the need for surgical improvisation. Ann Thorac Surg 2010;89:1789-96.

2. Muniappan A, Wain JC, Wright CD, et al. Surgical treatment of nonmalignant tracheoesophageal fistula: a thirty-five year experience. Ann Thorac Surg 2013;95:1141-6.

3. López A, Rodríguez P, Santana N, et al. Esophagobronchial fistula caused by traction esophageal diverticulum. Eur J Cardiothorac Surg 2003;23:128-30.

4. Ballehaninna UK, Shaw JP, Brichkov I. Traction esophageal diverticulum: a rare cause of gastro-intestinal bleeding. Springerplus 2012;1:50.

5. Pearson FG, Patterson GA. editors. Pearson's thoracic \& esophageal surgery. 3rd ed. Philadelphia: Churchill Livingstone/Elsevier, 2008.

6. Braghetto I, Cardemil G, Schwartz E, et al. Videothoracoscopic management of middle esophageal diverticulum with secondary bronchoesophageal fistula: report of a case. Surg Today 2008;38:1124-8.

7. Tomiyama K, Ishida $\mathrm{H}$, Miyake $\mathrm{M}$, et al. Benign acquired bronchoesophageal fistula in an adult. Jpn J Thorac Cardiovasc Surg 2003;51:242-5.

8. Akashi A, Ohashi S, Oriyama T, et al. Thoracoscopic

Cite this article as: Sun Y, Hao S, Yang Y, Guo X, Ye B, Zhang X, Li Z. Surgical management of acquired tracheo/ bronchoesophageal fistula associated with esophageal diverticulum. J Thorac Dis 2017;9(10):3684-3692. doi:10.21037/jtd.2017.09.81 treatment of esophagobronchial fistula with esophageal diverticulum. Surg Laparosc Endosc 1997;7:491-4.

9. Stewart WR, Klassen KP, Horava AP. Esophagobronchial fistula due to esophageal traction diverticulum; review of literature and report of case. AMA Arch Surg 1958;76:317-21.

10. Filston HC, Rankin JS, Kirks DR. The diagnosis of primary and recurrent tracheoesophageal fistulas: value of selective catheterization. J Pediatr Surg 1982;17:144-8.

11. Ke M, Wu X, Zeng J. The treatment strategy for tracheoesophageal fistula. J Thorac Dis 2015;7:S389-97.

12. Marulli G, Loizzi M, Cardillo G, et al. Early and late outcome after surgical treatment of acquired nonmalignant tracheo-oesophageal fistulae. Eur J Cardiothorac Surg 2013;43:e155-61.

13. Yalçin Ş, Ciftci AO, Karnak I, et al. Management of acquired tracheoesophageal fistula with various clinical presentations. J Pediatr Surg 2011;46:1887-92.

14. Devarbhavi HC, Alvares JF, Radhikadevi M. Esophageal tuberculosis associated with esophagotracheal or esophagomediastinal fistula: report of 10 cases. Gastrointest Endosc 2003;57:588-92.

15. Camargo JJ, Machuca TN, Camargo SM, et al. Surgical treatment of benign tracheo-oesophageal fistulas with tracheal resection and oesophageal primary closure: is the muscle flap really necessary? Eur J Cardiothorac Surg 2010;37:576-80.

16. Jung JH, Kim JS, Kim YK. Acquired Tracheoesophageal Fistula through Esophageal Diverticulum in Patient Who Had a Prolonged Tracheostomy Tube - A Case Report - . Ann Rehabil Med 2011;35:436-40.

17. Schweigert M, Dubecz A, Beron M, et al. Management of anastomotic leakage-induced tracheobronchial fistula following oesophagectomy: the role of endoscopic stent insertion. Eur J Cardiothorac Surg 2012;41:e74-80.

18. Buskens CJ, Hulscher JB, Fockens P, et al. Benign tracheoneo-esophageal fistulas after subtotal esophagectomy. Ann Thorac Surg 2001;72:221-4.

19. Bona D, Sarli D, Saino G, et al. Successful conservative management of benign gastro-bronchial fistula after intrathoracic esophagogastrostomy. Ann Thorac Surg 2007;84:1036-8. 